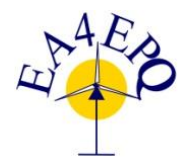

International Conference on Renewable Energies and Power Quality (ICREPQ'13) Bilbao (Spain), 20 $0^{\text {th }}$ to $22^{\text {th }}$ March, 2013

Renewable Energy and Pourer Qualim. Fournal (RE\&PQJ)

ISSN 2172-038 X, No.11, March 2013

\title{
Design and Deployment of the Askaryan Radio Array South Pole Autonomous Renewable Power Stations (AARPS)
}

\author{
D. Z. Besson ${ }^{1}$, D. M. Kennedy ${ }^{1}$, K. Ratzlaff ${ }^{2}$ and R. Young ${ }^{2}$ \\ ${ }^{1}$ Department of Physics and Astronomy \\ University of Kansas \\ 1082 Malott, 1251 Wescoe Hall Dr. - Lawrence, KS 66045, USA \\ Phone: +1-785-864-4626, Fax: +1-785-864-5262, e-mail: zedlam@ku.edu, dmkennedy@ku.edu \\ ${ }^{2}$ Instrumentation Design Laboratory \\ University of Kansas \\ 6042 Malott, 1251 Wescoe Hall Dr. - Lawrence, KS 66045, USA \\ Phone: +1-785-864-3754, e-mail: ratzlaff@ku.edu, rwyoung@ku.edu
}

\begin{abstract}
Research was initiated in 2009 to determine the feasibility of constructing $300 \mathrm{~W}$ autonomous renewable energy power stations at the South Pole. In January 2011, a test power station was constructed at the South Pole using three small scale wind turbines that included a system health monitor, meteorology and power instruments and remote communications pipeline. Significant testing and development was performed to prepare the hardware and electronics for the sub -40C environment. During December 2011, additional wind turbines and equipment were deployed at the South Pole to upgrade existing systems and perform additional testing. Results of field testing are presented.
\end{abstract}

\section{Key words}

Antarctica, Askaryan Radio Array, autonomous power.

\section{Introduction}

The ARA Autonomous Remote Power Stations (AARPS) were developed to support the Askaryan Radio Array (ARA) at the South Pole. Renewable power sources were selected to power the array due to high fuel costs associated with the remote location of stations and the requirement for power lines to be entrenched in the ice over great distances.

The Phase 1 Askaryan Radio Array is a $200 \mathrm{~km}^{2}$ array of radio antennas under construction for the purpose of detecting ultra high energy cosmic neutrinos [1]. Neutrinos with energies greater than $10^{18} \mathrm{eV}$ interact with the polar ice creating a cascading particle shower that produces coherent Cherenkov radio emission [2]. The extremely high radio transparency of the ice allows the radio signals to be detected over the great distances of this array.
The nature of the detector location and site characteristics produce a unique problem for powering the array. Wind and solar power combinations have proven to be successful near the Antarctic coast where wind speeds are high and construction sites are easily accessible. However, the South Pole is extremely remote with low wind speeds and sunlight only half the year.

The goal of this paper is to present (a) a method for providing reliable renewable power in remote Antarctic regions, (b) models for predicting wind turbine performance and the required battery buffering, (c) remote monitoring and communications with autonomous power stations, and (d) results from deployments and testing at the South Pole.

\section{Wind Turbine Selection}

Solar panels and wind turbines have previously been utilized in remote locations in Alaska, Antarctica and Greenland [3]. Wind turbines were initially selected without photovoltaic (PV) cells for deployment and testing due to the proven use of photovoltaic cells in the Antarctic environment such as at McMurdo Sound and significant research in the use of PV systems in polar environments [4]. Wind turbines were successfully deployed by our group during the 2010-2011 season. Subsequently, one PV cell and additional wind turbines were deployed during the 2011-2012 season.

The selection of an appropriate turbine depends on the local wind profile. For the South Pole, the wind profiles were based on near surface wind observation data provided by the National Oceanic and Atmospheric Administration (NOAA) / Oceanic and Atmospheric Research Earth System Research laboratory (OARES) / Global Monitoring Division (GMD) observatory at Amundsen-Scott South Pole Station [5]. 
The low wind speeds at the South Pole required selecting wind turbines with a very low start-up speed. Three turbines were selected to provide approximately $300 \mathrm{~W}$ to one detector node. Additional consideration in turbine and tower selection was the availability of logistical support. These factors led to the selection of the small scale wind turbines listed in Table I.

Table I. - Wind Turbine Selection

\begin{tabular}{|l|c|c|}
\hline \multicolumn{1}{|c|}{ Model } & Rating (Watts) & Season \\
\hline Bergey XL1 & 1000 & $2010-2011$ \\
\hline Hummer & 1000 & $2010-2011$ \\
\hline Raum Energy & 1500 & $2010-2011$ \\
\hline Whisper & 900 & $2011-2012$ \\
\hline Aero6gen-F & 240 & $2011-2012$ \\
\hline
\end{tabular}

Analysis of wind speeds for the South Pole showed that the Hummer $1 \mathrm{~kW}$ turbine at 20 meters would produce greater than $100 \mathrm{Watts}$ for $85 \%$ of 2010 (Figure 1).

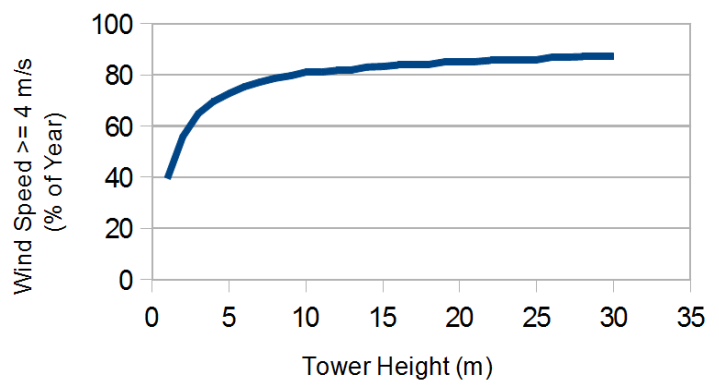

Figure 1: Minimum Wind Speed Availability for Hummer $1 \mathrm{~kW}$ Turbine as a Function of Tower Height.

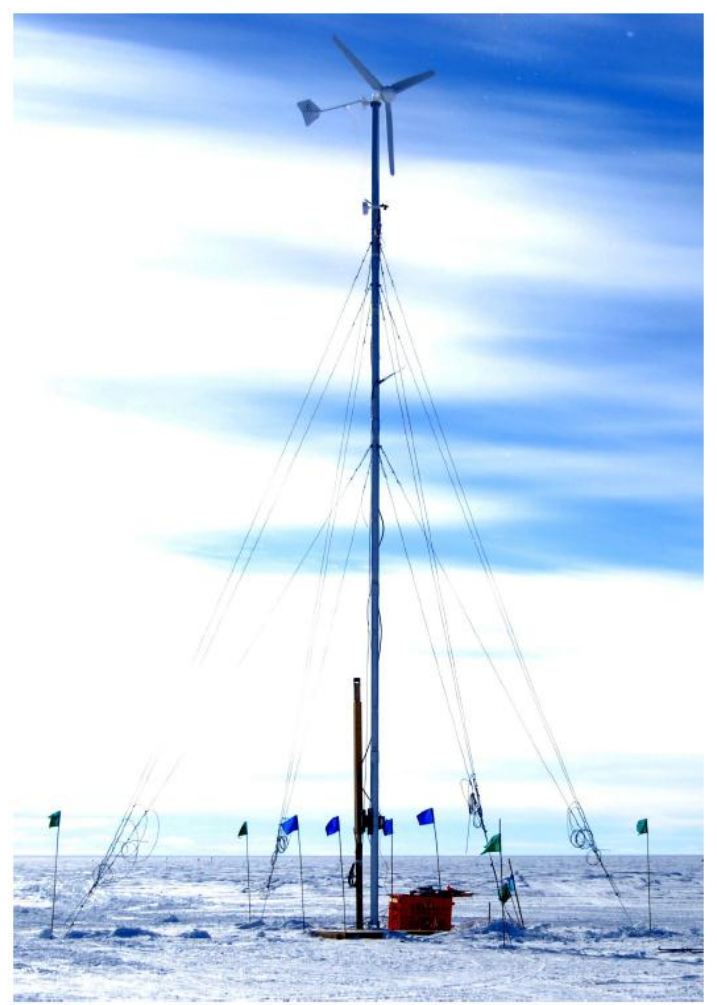

Figure 2: AARPS Hummer Wind Turbine at the South Pole, installed January 2011 [1].
Selecting multiple turbines allowed testing of different models for survivability and power production as well as reduced the inherent risks of damages and loss during shipping or mechanical failure after installation.

Each turbine utilized a different tower to allow testing different tower erection techniques with minimal personnel and equipment. These towers consisted of a tilt up lattice tower and two different types of monopoles.

\section{Cold Preparation}

The entire power system was developed to operate in temperatures below $-50 \mathrm{C}$ to as low as $-80 \mathrm{C}$. This consisted of cold-testing hardware and electronics. Power cables were frozen and then bent to determine the force required to reach a certain curvature without fracture. The cables would arrive at the construction site as coils that would have to be unwound and installed without damage or excessive labor.

Each of the turbines required disassembly to allow cold testing of the generator bearings. In all cases, the bearings seized at temperatures below -40C. Multiple types of grease were tested including Mobilgrease 33, Molykote 33, Royco 27. Each bearing was tested to determine the amount of grease required to achieve the desired performance.

A testing platform was created to facilitate testing of the electronics at freezing temperatures to verify proper operation as well as check for component failure. One of the turbines was driven by a motor with output power delivered to the electronics contained inside a freezer. An electric load was then placed on the inverter at different load levels.

The 12 Volt gel batteries used for power buffering underwent a series of charge and discharge cycles to determine the effects of temperature on battery storage capacity, charging rate and discharge rate. The battery testing results (Figures 3 and 4) showed that the batteries must be kept above $-5 \mathrm{C}$ due to losses in storage capacity. Subsequently, this required considerable heating of the electronics boxes to minimize thermal losses.

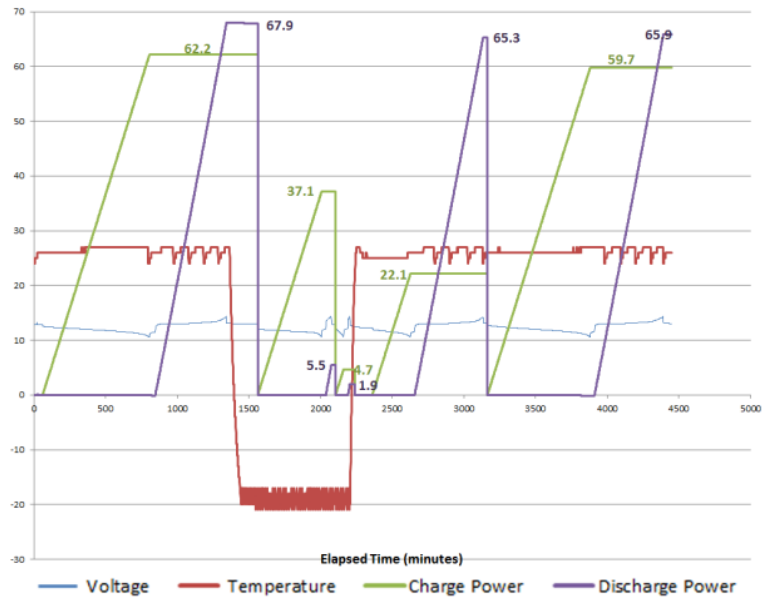

Figure 3: Battery Profile $-20 \mathrm{C}$ to $25 \mathrm{C}$. 


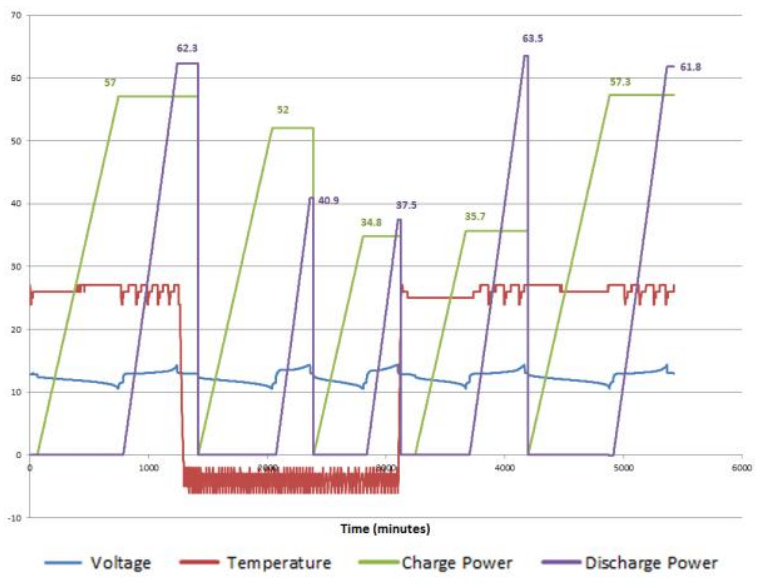

Figure 4: Battery Profile $-5 \mathrm{C}$ to $25 \mathrm{C}$.

Data collected from the 2010-2011 season indicated that 35 Watts were required to keep the System Health Monitor (SHM) boxes at $-5 \mathrm{C}$ for sufficient battery performance.

\section{Modelling}

Computer modelling was utilized to predict wind speeds at varying tower heights, power output for the different generators, and how battery buffering would affect the operational live time of the power stations.

\section{A. Wind as Function of Height Above Surface}

The NOAA data used for generator modelling was taken at 10 meters above the ice surface. A height correction model was used to provide an estimate for the percent gain in wind speed at higher tower heights while taking into account surface roughness [6]. The towers were constructed at heights ranging from 15 meters to 20 meters to make use of the higher wind speed within the means of the available construction equipment and personnel.

Figure 5 illustrates the South Pole wind speed profile at $2 \mathrm{~m}$ and $10 \mathrm{~m}$ for 2010 . For a turbine at 10 meters, wind speeds would be greater than a cut-in speed of $4 \mathrm{~m} / \mathrm{s}$ for $73 \%$ of the year. For a turbine at 2 meters, wind speeds would be greater than a cut-in speed of $4 \mathrm{~m} / \mathrm{s}$ for only $50 \%$ of the year. The tower height correction model closely approximated actual readings when predicting wind speeds at 10 meters using data collected at 2 meters.

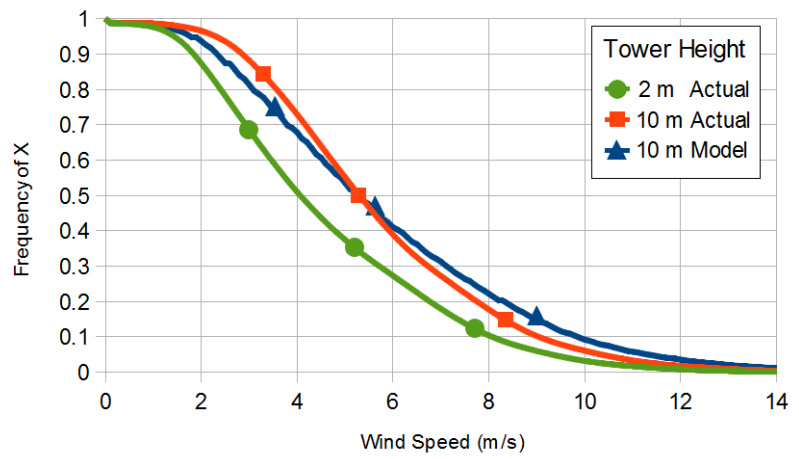

Figure 5: Tower Height Correction Model for South Pole Wind Speeds, 2010.

\section{B. Wind Turbine Power Output}

Historic wind power data was used with manufacturer's power production curves to estimate live time for the $300 \mathrm{~W}$ detector load. A model was created that combined the manufacturer's power curves with on site measured power output and wind speeds (Figure 6). With this model, a combination of wind turbines and photovoltaic cells is estimated to satisfy the required load at least $92 \%$ of the time and $97 \%$ of the time with battery buffering.

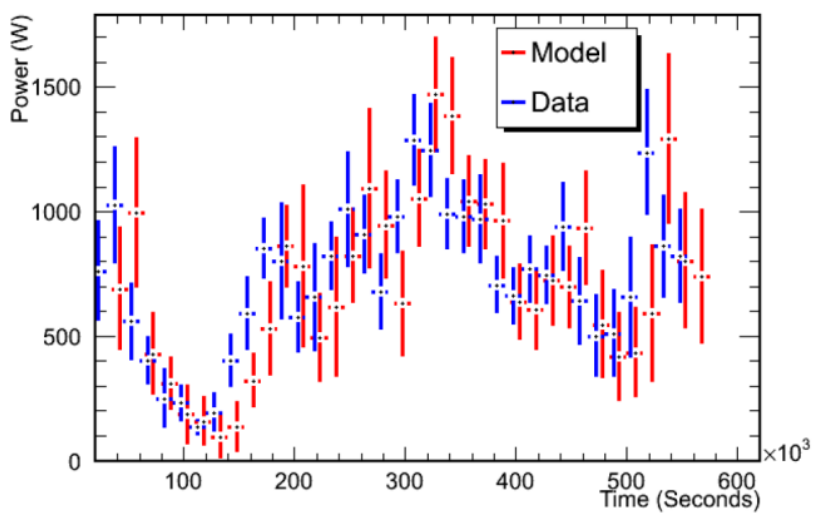

Figure 6: Comparison of Modelled vs. Measured Wind Turbine Performance; data taken from Jan. 26 - Feb. 1 [1].

\section{Battery Buffering}

A model of the charge and discharge characteristics for the Deka 8G31 12 Volt gel battery was combined with the generator power output model to analyse different levels of battery buffering using historical wind patterns.

The output of this model for the Bergey turbine is shown in Figure 7. For a given 15 Watt load, a single Bergey turbine was simulated to provide $90 \%$ uptime when paired with approximately 300 Amp-hours of battery buffering and no PV cell.

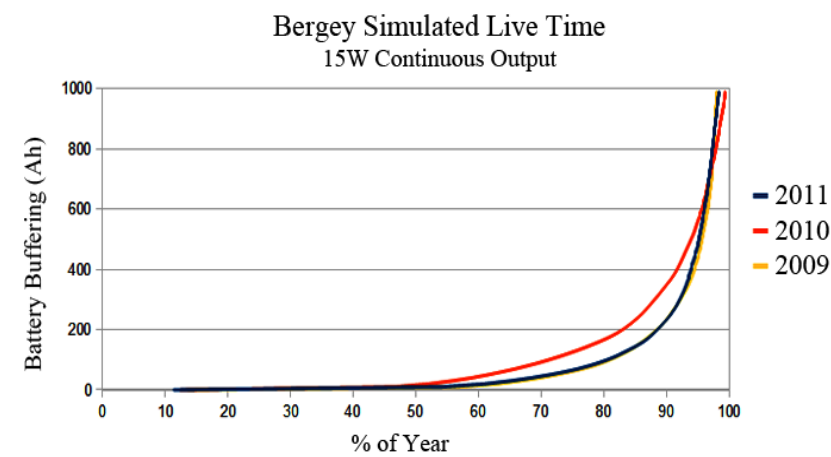

Figure 7: Bergey Simulated Live Time for 15 W Continuous Output.

\section{Remote Monitoring and Communications}

Generator operating parameters and weather conditions are continuously monitored and logged at regular intervals. This data is stored on an SD card at each station 
and transmitted via satellite to an online database. This data can then be viewed, downloaded and analysed over the internet. Direct communication with the system health monitor (SHM) boards is planned for remotely updating and tuning the control electronics.

\section{Results}

The highest performing turbine was the Hummer. Figure 8 shows a plot of the turbine output power vs. wind speed. The power output matched the expected cube of wind speed relationship with a curve fit of $\mathrm{P}$ (velocity) $\propto \mathrm{v}^{2.8}$. While this turbine has outperformed all others deployed by this group, a vibration developed in the tail that was severe enough to completely disable the turbine within weeks after construction.

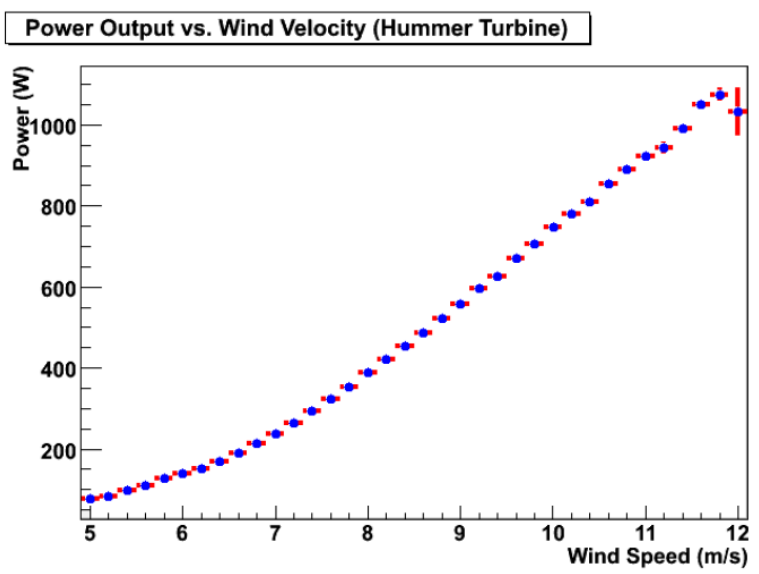

Figure 8: Plot of Power Output vs. Wind Velocity [1]

Temperature instruments were used to log temperatures on the towers, in the ice, and in the SHM boxes. These instruments were vital in remotely troubleshooting a fault that occurred in a SHM board. Once the power stations are deployed, the Antarctic winter prohibits personnel from revisiting the site for inspection for 9-12 months.

The PV cell deployed during the 2011-2012 season exceeded performance expectations (Figure 9). The panel was mounted vertically to facilitate capturing sunlight when the sun is just above the horizon. The higher efficiency at colder temperatures coupled with the albedo of the snow allowed the solar panel to satisfy power needs even when pointing away from the sun.

\section{References}

[1] P. Allison et al, "Design and Initial Performance of the Askaryan Radio Array Prototype EeV Neutrino Detector at the South Pole", arXiv:1105.2854v2 [astro-ph.IM].

[2] P. Miočinović, "Tuning into UHE Neutrinos in Antarctica The ANITA Experiment", arXiv:astro-ph/0503304v1.

[3] "Examples", PolarPower.org http://polarpower.org/examples/index.html

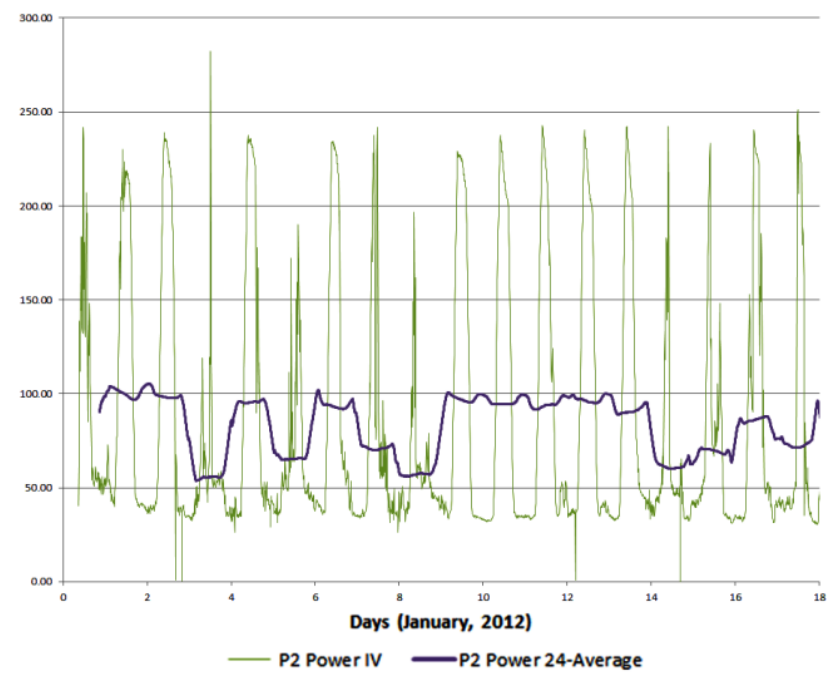

Figure 9: Test-bed PV Power Output.

\section{Conclusion}

With the exception of the Hummer, all wind turbines performed without failure. All remaining turbines produced lower power than expected. The Raum turbine had the most difficulty with sustained operation due to the extremely low wind speeds. The performance of the PV cell exceeded expectations.

The effective use of instrumentation, data logging, and remote monitoring created a detailed window into the daily operation of the power stations. Without this persistent window, remote troubleshooting and preparation for follow-up deployments would not have been nearly as successful. Remote monitoring and research continues for future deployments.

\section{Acknowledgement}

Support for this project was provided by the National Science Foundation through Grant NSF OPP-1002483, as well as the Raytheon Polar Services Corporation via field support at Amundsen-Scott Station. Additional support was provided by the Ice-Cube personnel for station installation.

[4] "Photovoltaic Power Systems Technology White Paper", PolarPower.org http://polarpower.org/static/docs/PVWhitePaper1_31.pdf

[5] NOAA / ESRL / GMD Meteorological Observations, ftp://ftp.cmdl.noaa.gov/met/

[6] Newcomb, M., "Tower Height Correction", http://icecube.wisc.edu/ mnewcomb/radio/wind/ 